Journal of Economics and Behavioral Studies

Vol. 5, No. 5, pp. 260-267, May 2013 (ISSN: 2220-6140)

\title{
Aggregate Outbound Tourism Demand in South Africa: an Econometric Analysis
}

\author{
${ }^{*}$ Emmanuel Ziramba1, Busani Moyo ${ }^{2}$ \\ ${ }^{1}$ University of Namibia, Namibia \\ 2University of South Africa, South Africa \\ *zirambae@gmail.com
}

\begin{abstract}
This paper, with the use of annual data covering the period 1975 to 2008, seeks to identify the determinants of outbound tourism demand (outbound tourist outflows) in South Africa. We employ cointegration analysis by utilising an autoregressive distributed lag (ARDL) approach proposed by Pesaran et al. (2001) to make inferences about the long run and short run relationships. The results indicate that in the long run, outbound tourism demand is influenced by the real domestic income and the relative prices. Our results indicate that outbound tourism demand is a luxury good with an income elasticity of 3.5. In the short run, only relative prices have an impact on outbound tourism demand in South Africa. Outbound tourism demand was found to be price inelastic in both periods.
\end{abstract}

Keywords: Tourism Demand, Econometric Analysis, South Africa

\section{Introduction}

Tourism is the world's largest sector, with annual revenues of almost $\$ 500$ billion and it accounts for roughly 35 per cent of exports of services and over 8 per cent of exports of goods (DTI, 2006). It is also estimated that about 340 million people are directly and indirectly employed in tourism and it is one of the top five sources of foreign exchange for about 83 per cent of the countries in the world (DTI, 2006). In South Africa, tourism is also one of the fastest growing sectors of the economy. Its contribution to the country's gross domestic product (GDP) increased from 4.6\% back in 1993 to 8.3\% in 2006 (DTI, 2006). Directly and indirectly, tourism constitutes approximately $7 \%$ of employment in South Africa and the government considers this sector as key in boosting the country's economic growth. There has been an increase in the number of tourist coming to South Africa in the past four decades even though the total number of visitors only surpassed a million in the 1990s. For the period 1980 to 1992 prior to the democratic elections, tourist visits increased by about 14\% per year, rising to about 33\% between 1992 and 2009 (Stats SA, 2010). Most of these visitors to South Africa came from mainland Africa particularly SADC whilst overseas tourists came from Europe, North America and Asia. Available 2010 statistics show that, overseas tourists came mainly from UK, 46585 (26,3\%); Germany, 21863 (12,3\%); USA, 14885 (8,4\%); The Netherlands, 11200 (6,3\%); France, 10752 (6,1\%); China, 5582 (3,2\%); Sweden, 5431 (3,1\%); and Australia, 5238 (3,0\%). These countries are the eight leading overseas tourist sources for South Africa accounting for about $68.7 \%$ of all inbound tourists visits. Although inbound tourists visits have been increasing over the years; outbound tourism was stagnant from 1975 up to 1992. This was probably due to the apartheid political regime and associated foreign exchange restrictions that made it difficult for most South Africans at that time to go for overseas holidays. However after the announcement of political reforms in 1992 outbound tourism increased by almost double (78\%) in 1993 and thereafter grew at an average rate of 32\% per annum until 2009 (Stats SA, 2010). Favorite long haul destinations include the UK, USA, Germany, The Netherlands, Australia and East Asian countries of Japan and China. There was however, a sudden drop of outbound visits in 2004 (see Fig 1 below) and according to Stats SA (2009), this was because of changes in the data collection system. This was a result of changes in the immigration Act No.13 of 2002 which resulted in information on arrival and departure of SA residents not being collected. Collection through the scanning of passports resumed after implementation of Act no.19 of 2004 (Stats SA, 2009). This explains why visits fell by 64\% between 2003 and 2004 before increasing by $424 \%$ in 2005 . 
Figure 1: Total outbound visits by South Africans

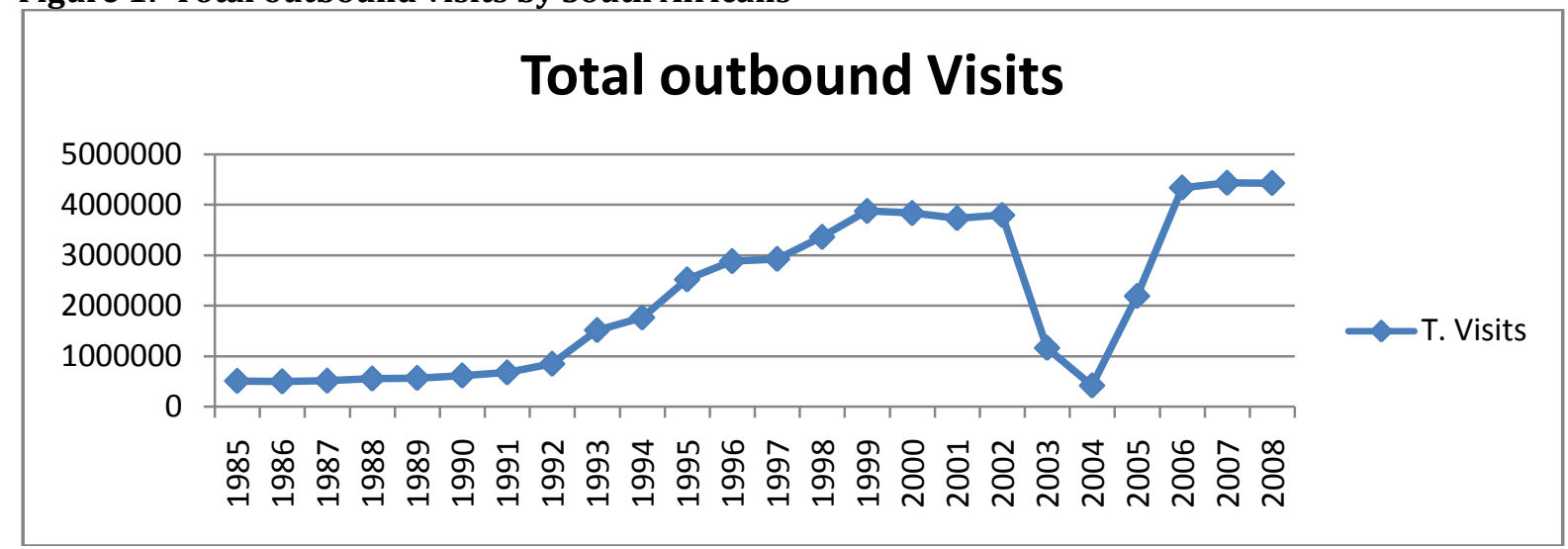

The main objective of this study is to examine the determinants of outbound tourism from South Africa over the period 1975 to 2008 using the bounds test approach to cointegration. Most of the tourism demand studies that have been done on South Africa have concentrated on inbound tourism demand (see Saayman et al, 2001 as well as Saayman and Saayman, 2008) and this paper therefore presents a departure from this approach. Outbound tourism is good in fostering international relations and is good for cross pollination of ideas. Thus this kind of tourism allows South Africans to gather experience in foreign countries and to use this experience to enhance the country's development. Outbound tourism can also be used to promote inbound tourism especially if South Africans travelling abroad exchange tourism related information about their country. However it should also be emphasized that outbound tourism also exerts pressure on the country's foreign currency reserves. This paper is organized as follows, the next section reviews empirical literature on outbound tourism demand. Section 3 discusses the empirical methodology employed in this study. Section 4 gives a description of the data, their definitions and sources. The empirical results are presented and discussed in section 5 . The last section gives a summary of our findings and conclusions.

\section{Literature Review}

A handful of studies have been done both in developed and developing countries to examine the determinants of inbound and outbound tourism demand using different variants of cointegration techniques. Studies on outbound tourism demand include Halicioglu (2010), Mitchell and Campbell (2007), Song et al (2000), Lim (2004), Seo et al (2009) and Sathiendrakumar and Watson (1997). Halicioglu (2010) examined aggregate tourism outflows in Turkey using annual data from 1970 to 2005 using the bounds testing to cointegration proposed by Pesaran et al (2001). Using aggregate tourist flows, real aggregate income and exchange rate adjusted relative prices; he found that income and relative prices Granger causes outbound tourism. The estimated income elasticity and price elasticity of 1.42 and -0.18 respectively imply that tourism is a luxury good and thus price policies will not be effective in regulating outbound tourism demand.Mitchell and Campbell (2007) also examined aggregate tourism expenditure outflows in Barbados using annual data covering period 1973 to 2003. They used Vector Error Correction (VEC) approach proposed by Johansen and Juselius (1990) and controlled for real GDP per capita, passenger fares (a proxy for tourism cost) and the real effective exchange rate. Their results show that in the long run, outbound tourism demand is influenced by the exchange rate, per capita income and the cost of tourism whilst in the short run; only the exchange rate and the cost of tourism have an impact on outbound tourism demand. They also found that real per capita income has the greatest impact on outbound tourism in the long run while the cost of tourism has the greatest impact in the short run. Estimated elasticities show that cost of tourism is unitary elastic whilst income elasticity is consistent with the fact that tourism in Barbados is a luxury good. Song, et al (2000) conducted an empirical study of outbound tourism demand in the UK using annual data from 1965 to 1994. Their aim was to construct and estimate outbound tourism demand models according to the holiday destinations of UK residents and to generate forecasts of UK demand for overseas holidays. They estimated 12 outbound models using 12 UK tourist destinations and used a number of diagnostic tests to test for model 
misspecification ${ }^{1}$. To measure the influence on outbound tourism demand, they used co-integration analysis and a two-stage error correction approach, developed by Engle and Granger (1987). They also constructed a preference index to capture the influence of social cultural and psychological factors on tourist decisions concerning overseas holiday destinations. Total holiday visits per capita to each destination by a UK resident was regressed on the cost of living index in each destination, measured by the consumer price index and adjusted by the exchange rate, the explicit deflator of UK, total consumer expenditure abroad adjusted by the corresponding exchange rate and a preference index. They found that the long-run income elasticities for all models ranged from 1.70 to 3.90 with a mean of 2.367 while the short-run elasticities were estimated at 1.05 and 3.78 respectively and the mean was 2.216 . These suggest that overseas holidays for UK residents are highly income elastic, and that although the costs of overseas holidays remained an important factor in the determination of international tourism demand, the demand for UK outbound tourism was also relatively own-price elastic. These findings are similar to those obtained by Halicioglu (2010) for Turkey.

Lim (2004) analysed the pattern of tourist arrivals from South Korea to Australia using seasonally unadjusted quarterly data for the period 1980 to 1999. In her model she controlled for income measured using real GDP, relative prices calculated using ratio of the two country's consumer price index and the real effective exchange rate as well as the lagged value of tourist arrivals to capture the hysteresis effect of past visits. She also found that international tourism demand by South Korea is both income elastic and price elastic confirming the common finding in the literature that tourism is a luxury good. To eliminate the trend and cyclical components on tourist arrivals, she used the ratio to moving average technique and estimated her demand function using OLS. She found income, relative prices and exchange rate to have a significant effect on tourist arrivals from South Korea. Seo et al., (2009) investigated the significance of South Korean outbound tourism to Jeju Island and three other Asian destinations (Philippines, Singapore and Thailand) using multivariate generalized autoregressive heteroscedasticity MGARCH model with dynamic conditional correlation (DCC) and the vector error correction model (VEC). They used DCC to examine the dynamic structure of the interdependence and dependence effects of international tourism demand and the VEC to estimate the determinants of conditional correlations. They used monthly Korean outbound data from April 1980 to June 2006. Their results show that the determinants of conditional correlations of South Korean outbound tourism are different for each destination and the exchange rate is a better indicator than other economic variables. Using an econometric approach similar to Song et al (2000), Sathiendrakumar and Watson (1997) attempted to explain the factors determining outbound tourism from Singapore. Unlike the study by Song et al (2000) they estimated a model for per capita tourism expenditure as a function of the exchange rate and per capita income over the time period 1968 to 1995. After reparameterisation, the final specification of the model was one that expressed a relationship between the change in tourism expenditure abroad and the dependent variables such as time, a quadratic time trend, the lags of tourism expenditure abroad, the lag of GDP per head, and the change in GDP per head. Based on the estimated coefficients, they concluded that a dollar increase in per capita GDP would lead to an increase in tourism expenditure abroad by Singaporean tourists by 4.6 cents. Additionally, a unit increase in the exchange rate, expressed in the number of Singaporean dollars per U.S. dollar, appeared to reduce per capita tourism expenditure of Singaporean tourists abroad by 3.6 cents per resident.

\section{Methodology}

Outbound tourism demand has not received as much attention in the empirical literature as inbound tourism. Notable studies that analyze outbound tourism demand include Halicioglu (2010), Song et al. (2000), Lim (2004), Mitchell and Campbell (2007). A number of variables have been included in the modelling of outbound tourism demand. The most prominent variables are real aggregate income measure, a price variable and in some case a price variable for substitute destination(s). Studies like Song et al (2000) include a destination preference index. Some studies have also included dummies to account for seasonality and various shocks that may have impacted the outbound flow of people. Our aggregate outbound tourism demand model for South Africa assumes that total tourist flows from South Africa are a function of the level of real income, the exchange rate-adjusted relative prices of tourism, travel cost and a dummy variable (D92)

${ }^{1}$ They used the Jarque-Bera normality tests, Breusch Godfrey test for serial correlation, the Engle autoregressive conditional heteroscedasticity test, Ramsey RESET and Chow F- tests for functional form and predictive failure. 
which accounts for the readmission of South Africa into the world community in 1992 when apartheid was abolished as well as the effects of relaxation of exchange controls on holiday allowances with effect from 1994. Following the empirical literature on tourism economics we specify our aggregate outbound tourism demand model for South Africa in log linear form as follows:

$\ln V_{t}=\beta_{0}+\beta_{1} \ln Y_{t}+\beta_{2} \ln P_{t}+\beta_{3} \ln T C_{t}+\beta_{4} D 92+\varepsilon_{t}$

Where $\mathrm{V}$ is the aggregate tourist flows from South Africa, $\mathrm{Y}$ is real domestic income (real GDP), $\mathrm{P}$ is exchange rate-adjusted relative prices, TC is the transportation cost index and D92 is a dummy variable defined as D92 = 1 for the period 1992 onwards and D92=0for the period before 1992, $\varepsilon$ regression residual, which is assumed not to be serially correlated. The estimated parameter coefficients represent elasticities.

An increase in real domestic income is expected to increase outbound tourism demand as it results in higher economic activity. The coefficient of income, $\beta_{1}$ is therefore expected to be positive. Coefficients $\beta_{2}$ and $\beta_{3}$ are expected to be less than zero according to economic theory. The coefficient on the dummy is expected to be positive according to the way the dummy is measured. The bounds test approach to co integration does not require precise knowledge of the order of integration or cointegration ranks of the variables provided none of the variables is integrated of order two. The test consists of estimating the following unrestricted error correction model (UECM) of the form:

$$
\begin{aligned}
& \Delta \ln V_{t}=\alpha_{0}+\alpha_{1} \ln V_{t-1}+\alpha_{2} \ln P_{t-1}+\alpha_{3} \ln Y_{t-1}+\alpha_{4} \ln T C_{t-1}+\alpha_{5} D 92+\sum_{i=1}^{m} \delta_{1 i} \Delta \ln V_{t-i}+\sum_{i=0}^{m} \delta_{2 i} \Delta \ln P_{t-i} \\
& +\sum_{i=0}^{m} \delta_{3 i} \Delta \ln Y_{t-i}+\sum_{i=0}^{m} \delta_{4 i} \Delta \ln T C_{t-i}+\varepsilon_{t}
\end{aligned}
$$

Here $\Delta$ denotes the first difference operator; the other variables are as defined above. The $\mathrm{F}$ test proposed by Pesaran et al. (2001) can be used to determine whether a long-run relationship exists through testing the joint significance of the lagged levels of the variables. If such a relationship exists among the variables, the $\mathrm{F}$ test indicates which variable should be normalized. The bounds test methodology suggests analysing the null hypothesis of no co-integration through a joint significance test of the lagged levels of the variables. The null hypothesis of no cointegration among the variables in equation (2) is $\left(H_{0}: \alpha_{1}=\alpha_{2}=\alpha_{3}=\alpha_{4}=0\right)$ against the alternative hypothesis $\left(H_{1}: \alpha_{1} \neq 0\right.$, or $\alpha_{2} \neq 0$, or $\alpha_{3} \neq 0$, or $\left.\alpha_{4} \neq 0\right)$.

We test the null hypothesis of no co-integration by means of the F-test. Pesaranet al., (2001) have established that, under the null hypothesis of no co-integration and regardless of the degree of integration of the variables, the asymptotic distribution of the obtained $F$-statistic is non-standard. It follows an asymptotic $\chi^{2}(\mathrm{~m})$ under the null, where $\mathrm{m}$ is the number of restrictions. They develop two bounds of critical values for the different model specifications: upper bound applies when all variables are integrated of order one, I(1) and the lower bound applies when all the variables are stationary, I(0). However, these critical values are generated on sample sizes of 500 and 1000 observations and 20000 and 40000 replications, respectively. Narayan and Narayan (2005) argue that such critical values cannot be used for small sample sizes like the one in this study. Given the relatively small sample size in the present study (40 observations) we extract the appropriate critical values from Narayan (2005) which were generated for small sample sizes of between 30 and 80 observations. If the computed $F$-statistic, for a chosen level of significance, lies outside the critical bounds, a conclusive decision can be made regarding co integration without knowing the order of integration of the regressors. If the estimated test statistic is higher than the upper bound, the null hypothesis of no cointegration is rejected. If the $F$-statistic is lower than the lower bound then the null hypothesis cannot be rejected. If the $F$-statistic lies between the lower and the upper bounds, conclusive inference cannot be made. By adopting Pesaran et al.'s (2001) approach for co-integration analysis, a pre-test for unit root (degree of integration) of the interested series is not necessary.

The chosen methodology, which is based on the estimation of an unrestricted error-correction model (UECM), has certain preference over other co integration tests. First, Pattichis, (1999) has argued that the UECM is likely to have better statistical properties because it does not push the short-run dynamics into the residual term as in the Engle-Granger (1987) technique. Second, it can be applied to studies that have finite samples unlike the Engle-Granger (1987) approach, which suffers from considerable small sample bias (Mah, 
2000). Third, the bounds test procedure is applicable irrespective of whether the underlying explanatory variables are integrated of order zero (I (0)) or one (I (1)) (Mah, 2000). In other words, it avoids the pretesting problems associated with standard co-integration analysis which requires the classification of variables into I (0) and I (1) (Pesaran et al. 2001). Fourth, another important advantage of the bounds test procedure is that estimation is possible even when the explanatory variables are endogenous, and is sufficient to simultaneously correct for residual serial correlation. However, it has to be pointed out that this procedure (method) is inappropriate if there is more than one co integrating relationship involving the dependent variable. In our case this does not apply since we only have two variables in our system.

Data definitions and sources: Annual data for the period 1975-2008were collected from various sources such as International Financial Statistics, the Direction of Trade Statistics, Statistics South Africa and the South African Reserve bank. $\mathrm{V}$ is the total tourist outflows in thousands. $\mathrm{Y}$ is the real gross domestic product (GDP) in millions of Rands with 2000 as the base year whilst TC is a travel cost index based on the per barrel spot oil prices with $2000=100^{2}$. $\mathrm{P}$ is a basket of trade-weighted and exchange rate-adjusted relative prices between South Africa and her five major trading partners. We used this variable as a proxy as there is no data on the tourist destinations that South African tourists visited over the estimation period. The major trading partners for South Africa are the United States of America, the United Kingdom, Germany, Japan and Netherlands. These five countries were visited by about forty percent of South African tourists in the year 2000. We formed trade shares on the basis of the shares of trade volumes (exports and imports) in the total trade volume. Following Halicioglu (2010) we define P as:

$$
P=\left(\frac{C P I_{W}}{C P I_{S A} * E R_{W}}\right),
$$

Where $\mathrm{CPI}_{W}$ is the weighted consumer price index of South Africa's five major trading partners, $\mathrm{CPI}_{\mathrm{SA}}$ is South Africa's consumer price index and $\mathrm{ER}_{\mathrm{W}}$ is the weighted nominal exchange rates between South Africa and her five major trading partners. Trade data for the weight calculation are in US\$ millions and are deflated by the US CPI. The CPIs are based on $2000=100$.

\section{Results}

Although the bounds test approach to cointegration does not require precise knowledge of the order of integration of the series, we tested for unit roots in order to make sure that none of the variables is integrated of order two. We used the standard augmented Dickey and Fuller (1979) and the Phillips and Perron (1988) tests to test the univariate properties of the series. The unit root test results are reported in Table 1. For all the variables the null hypothesis of a unit root could not be rejected in levels for both tests. However, the unit root null hypothesis was rejected in first differences. This suggests that all the variables have a unit root and therefore are integrated of order one.

Table 1: Unit root test results

\begin{tabular}{lllll}
\hline Variable & \multicolumn{2}{c}{ ADF } & PP \\
\cline { 2 - 5 } & level & First difference & level & First difference \\
\hline $\ln \mathrm{V}_{\mathrm{t}}$ & -3.027 & $-5.333^{* * *}$ & -2.409 & $-5.618^{* * *}$ \\
& $(-3.212)$ & $(-4.284)$ & $(-3.209)$ & $(-4.273)$ \\
$\ln \mathrm{Y}_{\mathrm{t}}$ & -0.334 & $-3.698^{* *}$ & -0.771 & $-3.905^{* *}$ \\
& $(-3.212)$ & $(-3.568)$ & $(-3.210)$ & $(-3.558)$ \\
$\ln \mathrm{P}_{\mathrm{t}}$ & -1.908 & $-4.895^{* * *}$ & -2.051 & $-4.717^{* * *}$ \\
& $(-3.210)$ & $(-4.285)$ & $(-3.210)$ & $(-4.273)$ \\
$\ln \mathrm{TC}$ & -1.010 & $-5.237_{\mathrm{t}}^{* * *}$ & -1.135 & $-5.236^{* * *}$ \\
& $(-3.210)$ & $(-4.273)$ & $(-3.210)$ & $(-4.273)$ \\
\hline
\end{tabular}

**, $* * *$ denote $5 \%$ and $1 \%$ level of significance respectively. Note that trend and intercept were used in the tests. The numbers in the parentheses for levels represent $10 \%$ critical values.

\footnotetext{
${ }^{2}$ Oil prices were obtained from: www.forecasts.org
} 
In order to perform bounds test we estimated a parsimonious unrestricted error correction model in the form of equation (2). Given our sample size, we start by introducing a lag length of two for the differenced variables. Following Hendry et al. (1984), we successively drop statistically non-significant variables. The preferred parsimonious UECM was used to compute the F-statistic that was used test for cointegration. Based on the estimated parsimonious UECM; we performed the bounds test using the following model specifications: unrestricted intercept and no trend (case III). We used the F- test to test for the joint significance of the lagged level variables in equation (2). The results of the bounds test are presented in Table 2. The computed $F$-statistic is larger than the upper critical value. Thus, the null hypothesis of no co integration, that is, $H_{0}: \alpha_{1}=\alpha_{2}=\alpha_{3}=\alpha_{4}=0$, is rejected and we conclude that there is a stable long-run relationship among tourist outflows, real domestic income, travel costs and relative price. The appropriate small sample critical values come from Narayan (2005).

Table 2: Bounds tests co-integration test results

\begin{tabular}{llll}
\hline Dependent variable & F-statistic & $\begin{array}{l}\text { Critical bounds at 5\% } \\
\text { Lower bound } \mathbf{( 0 )}\end{array}$ & Upper bound (1) \\
\hline$\Delta \ln V_{\mathrm{t}}$ & $5.955^{* *}$ & 3.276 & 4.630 \\
\hline
\end{tabular}

*** Statistical significance at $1 \%$ level.

Having found a long run relationship between tourist outflows, real domestic income, travel costs and relative prices when tourist outflow is the dependent variable, we estimated the long run elasticities. We investigate the impact of real domestic income and relative prices on the tourist outflows. We used two estimators, namely the ordinary least squares (OLS) and the autoregressive distributed lag (ARDL, $(\mathrm{k}, \mathrm{l}, \mathrm{m}, \mathrm{n})$ ) model.

$\ln V_{t}=\beta_{0}+\beta_{1} D 92+\sum_{i=1}^{k} \alpha_{1 i} \ln V_{t-i}+\sum_{i=0}^{l} \alpha_{2 i} \ln P_{t-i}+\sum_{i=0}^{m} \alpha_{3 i} \ln Y_{t-i}+\sum_{i=0}^{n} \alpha_{4 i} \ln T C_{t-i}+\varepsilon_{t}$

For the ARDL model, a maximum of 2 lags was used. The estimated model presented here is based on minimizing the Akaike Information Criterion. The empirical results obtained through normalizing on the log of tourist outflows ( $\mathrm{lnV}$ ) in the long-run are reported in Table 3. As can be seen from Table 3 all the variables have the expected signs and are significant except travel costs. Thus, in the long run outbound tourism demand in South Africa is determined by real domestic income and relative prices. The estimated coefficients represent elasticities. The income elasticity for outbound tourism demand is quite high at 3.5. This means that a 1 percent increase in real domestic income will lead to a 3.5 percent increase in outbound tourist visits by South African residents. Outbound tourism demand is found to be price inelastic with an elasticity of 0.286 . Thus, a 10 percent increase in relative prices will reduce outbound tourist visits by 2.86 percentage points. These findings on the income variable confirm the results found by Halicioglu (2010) in the case of Turkey, Lim (2004) in South Korea, Song, et al (2000) in the case of the United Kingdom and Mitchell and Campbell (2007)in Barbados. The dummy has a positive and significant impact of tourism demand. Thus, the readmission of South Africa into the international community in 1992 as well as the relaxation of exchange controls on holiday allowances with effect from 1994 led to an increase in outbound tourism demand.

Table 3: Long-run results

\begin{tabular}{|c|c|c|}
\hline Variable & Coefficient & t-Statistic \\
\hline $\ln Y_{t}$ & $3.530 * *$ & 2.179 \\
\hline $\ln P_{t}$ & $-0.286^{*}$ & -1.948 \\
\hline $\ln \mathrm{TC}_{\mathrm{t}}$ & -0.360 & -0.848 \\
\hline D92 & $0.999 * * *$ & 3.449 \\
\hline Constant & $-33.707^{*}$ & -1.760 \\
\hline Adjusted R-squared & 0.835 & \\
\hline Durbin-Watson stat & 1.889 & \\
\hline
\end{tabular}


The short-run dynamics of the outbound tourism demand were analyzed by estimating a general error correction model specified in equation (4):

$\Delta \ln V_{t}=\lambda_{0}+\lambda_{1} D 92+\sum_{i=1}^{k} \eta_{1 i} \Delta \ln V_{t-i}+\sum_{i=0}^{l} \eta_{2 i} \Delta \ln P_{t-i}+\sum_{i=0}^{m} \eta_{3 i} \Delta \ln Y_{t-i}+\sum_{i=0}^{n} \eta_{4 i} \Delta \ln T C_{t-i}+\lambda_{2} E C T_{t-1}+\mu_{t}$

Here ECT is the error correction term obtained from the cointegration relationship and its coefficient $\left(\lambda_{2}\right)$ represents the speed of adjustment to long-run equilibrium, $\mu$ is the error term and all the other variables are as defined before. The results for the short-run model are reported in Table 4. These results indicate that short-run outbound tourism demand is influenced by relative prices only as the other variables are insignificant. The error correction term $\mathrm{ECT}_{\mathrm{t}-1}$ in the short-run general error correction model (ECM) is statistically significant with a negative sign, which confirms that a long-run equilibrium relationship exists between outbound tourism demand and its determinants. The coefficient of the error correction term is 0.648 . This means that if the system is shocked convergence to long-run equilibrium is relatively fast with about65 percent of the adjustment being completed in first year, with full convergence being achieved after about 1.54 years.

Table 4: Short-run results

\begin{tabular}{lll}
\hline Variable & Coefficient & t-Statistic \\
\hline$\Delta \ln \mathrm{Y}_{\mathrm{t}}$ & 1.209 & -0.608 \\
$\Delta \ln \mathrm{P}_{\mathrm{t}}$ & $-0.293^{*}$ & -1.907 \\
$\Delta \ln \mathrm{C}_{\mathrm{t}}$ & -0.296 & -0.919 \\
$\mathrm{D} 92$ & 0.006 & 0.056 \\
ECT $_{\mathrm{t}-1}$ & $-0.648^{* * *}$ & -4.421 \\
Adjusted R-squared & 0.391 & \\
\hline
\end{tabular}

***, ${ }^{*}$ denote statistical significance at $1 \%$ and $10 \%$ levels, respectively.

\section{Conclusion}

In this paper we examined the determinants of outbound tourism demand in South Africa over the annual period 1975-2008. We employed the (bounds test) autoregressive distributed lag (ARDL) approach to test for cointegration developed by Pesaran et al. (2001). Both the unrestricted error correction model and the general short-run error correction model were subjected to a set of specification and diagnostic tests in order to check their adequacy. The Ramsey RESET (2) test does not reject the null hypothesis of no misspecification in the functional form for both models. Both models' residuals are normally distributed as confirmed by the Jarque Bera test. The Breusch-Godfrey LM test does not reject the null hypothesis of no serial correlation in the residuals for both models. There was no evidence of autoregressive conditional heteroscedasticity and hetrescedasticity as confirmed by the ARCH (2) and White's tests. The bounds test results confirm the presence of a long-run relationship between tourist outflows from South Africa and real domestic income, travel cost and relative price. Our results suggest that the most significant factor determining outbound tourist flows is real domestic income, which is followed by the relative prices. Transport cost is found not to have any impact in both the short and long-run periods. The empirical results suggest that the long-run income elasticity of outbound tourism demand is 3.53. This estimate implies that overseas holidays are highly income elastic, suggesting that such trips are regarded as a luxury good. Our results also suggest that the demand for outbound tourism is own- price inelastic with an elasticity of -0.286 . The results also suggest that the readmission of South Africa into the international community in 1992 and the relaxation of exchange controls on holiday travel in 1994 significantly increased outbound tourist flows from South Africa. Our results suggest that countries with higher levels of income will most likely experience higher levels of tourist outflows. Since outbound tourism can put pressure on foreign reserves, governments have to find ways of 
boosting these foreign currency reserves or ways of controlling access to them ${ }^{3}$. The government's choice of strategy will depend on the benefits vis a vis the costs to the country of promoting this kind of tourism as well as the proportion of total foreign reserves used for outbound tourism. With data availability, disaggregated outbound tourism demand for South Africa into each of the major destinations can be analyzed. This will shed more light as to what determines tourism demand into each of the markets. We believe that the drivers of outbound tourism are not the same in each destination and this will help in extending this study.

\section{References}

Department of Trade and Industry DTI. (2006). Tourism sector report.

Dickey, D. A. \& Fuller, W. A. (1979). Distribution of the Estimators for Autoregressive Time Series with a unit root. Journal of the American Statistical Association, 73(366), 427-431.

Engle, R. E. \& Granger, C. W. J. (1987). Cointegration and error correction: Representation, Estimation, and testing. Econometrica, 55, 251-76.

Halicioglu, F. (2010). An Econometric Analysis of Aggregate Outbound Tourism Demand of Turkey. Tourism Economics, 16(1), 83-98.

Hendry, D. F., Pagan, A. \& Sargan, J. D. (1984). Dynamic specification. In Z. Griliches and M. Intrilligator (Eds), Handbook of Econometrics 2. Amsterdam: North Holland

Johansen, S. \& Juselius, K. (1990). Maximum likelihood estimation and inference on cointegration with application to the demand for money. Oxford Bulletin of Economics and Statistics, 52, 169-209.

Lim, C. (2004). The major determinants of Korean outbound travel to Australia. Mathematics and Computers in Simulation, 64, 477-485.

Mah, J. S. (2000). An empirical examination of the disaggregated import demand of Korea- the case of information technology products. Journal of Asian Economics, 11, 237-244.

Mitchell, T. K. \& Campell, T. (2007). Determinants of outbound holiday travel for Barbados. Tourism Analysis, $12(1-2), 77-82$.

Narayan, P. K. (2005). The saving and investment nexus for China: evidence from co-integration tests. Applied Economics, 37(17), 1979-1990.

Narayan, P. K. \& Narayan, S. (2005). Estimating income and price elasticities of imports for Fiji in a cointegration framework. Economic Modelling, 22, 423-438.

Pattichis, C. A. (1999). Price and income elasticities of disaggregated import demand: results from UECMs and an application. Applied Economics, 31, 1061-1071.

Pesaran, M. H., Shin, Y. \& Smith, R. J. (2001). Bounds Testing Approaches to the Analysis of Level Relationships. Journal of Applied Econometrics, 16(3), 289-326.

Phillips, P. C. B. \& Perron, P. (1988). Testing for a unit root in time series regression. Biometrika, 75, 335-46.

Saayman, A. \& Saayman, M. (2008). Determinants of inbound tourism to South Africa. Tourism Economics, 14(1), 81- 96.

Saayman, M., Saayman, A. \& Rhodes, J. A. (2001). Domestic tourist spending and economic development: the case of the North West Province. Development Southern Africa, 18(4), 443-455.

Sathiendrakumar, R. \& Watson, R. (1997). Outbound Tourism from Singapore. Asian Research Centre, Working Paper, 69.

Seo, J. H., Park, S. Y. \& Yu, L. (2009). The analysis of the relationships of Korean outbound tourism demand: Jeju Island and three international destinations. Tourism Management, 30, 530-543.

Song, H., Romilly, P. \& Liu, X. (2000). An Empirical Study of Outbound Tourism Demand in the UK. Applied Economics, 32(5), 611-624.

Statistics South Africa (2009 -2010). Tourism and Migration reports.

\footnotetext{
3 The government can also restrict outbound tourism demand in order to preserve foreign exchange via different forms of obstacles and policies, such as excess exit taxes, restrictions on issuing passports, limiting the amount of foreign currency to take abroad and multiple rates for the different purposes of foreign country visits (Halicioglu, 2010).
} 